\title{
Monitoring land Cover Changes and Fragmentation dynamics in the subtropical thicket of the Eastern Cape Province, South Africa.
}

\author{
Adolph Nyamugama ${ }^{1,2}$, Vincent Kakembo ${ }^{1}$ \\ ${ }^{1}$ Department of Geosciences, Nelson Mandela Metropolitan University, Port Elizabeth, South Africa \\ ${ }^{2}$ Agricultural Research Council - Institute for Soil, Water and Climate, Pretoria, South Africa
}

DOI: http://dx.doi.org/10.4314/sajg.v4i4.4

\begin{abstract}
Land cover change trends and fragmentation dynamics in the Great Fish River Nature Reserve (GFRNR) and surrounding settlements were monitored for a period of 38 years, in the intervals of 1972-1982, 1982-1992 and 2002-2010. Gaining an understanding of these trends and dynamics is vital for land management and combating desertification. Monitoring land cover change and fragmentation dynamics was conducted using LandSAT MSS, LandSAT4TM and LandSAT 7ETM and SPOT 5 High-resolution Geometric (HRG) imagery. The objected-oriented supervised approach and cross-classification algorithm were used for classification of the satellite imagery and change detection respectively. Landscape fragmentation was analysed using FRAGSTATS 3.3® class level land metrics. Overall, a decrease in the land area under intact and transformed thicket was realised. Degraded thicket, grassland and bare surfaces increased over the same period. Landscape metric analyses illustrated an increase in vegetation fragmentation over the 38-year period, as demonstrated by an increase in the number of patches (NP) and a decrease in the Largest Patch Index (LPI), particularly for intact and transformed thicket. Baseline land use/cover maps and fragmentation analyses in a temporal framework are valuable for gaining insights into, among other things, carbon stock change trends.
\end{abstract}

Keywords: Land cover change, fragmentation; remote sensing; Geographic information systems (GIS)

\section{Introduction}

Human activities have become an important factor in global change processes (Petit \& Lambin, 2002) in the wake of the surge in global population. According to Green et al. (1994), land use and cover, change processes are caused by the interaction between physical, biological and social forces. These processes can lead to the conversion of productive land into degraded land, loss of species and emission of greenhouse gases into atmosphere 
(Houghton, 1994, Ojima et al., 1994, Turner 1994, De Meuelenaere et al., 2013). Land cover analysis provides the basis for understanding historical land use practices, present use patterns and prospective trends (Lal, 2007). It also provides baseline information for comprehending global carbon dynamics (Sanchez -Azofeifa et al., 2009). According to Prentice et al. (2007), approximately two-thirds of the population living in rural areas of central and southern Africa depend on agriculture and other natural resources for their economic and social needs. Therefore, pressure has been exerted on the land, resulting in the deterioration of its quality (Amissah-Arthur and Miller, 2002; Sigwela et al; 2009). The effects felt at local and regional level have an important influence on global scale processes. Southworth et al. (2004) observed that landscape fragmentation analysis is crucial for the interpretation of the effect of land cover changes on a particular habitat, through the calculation of each land cover class landscape metric. Therefore, the integration of remote sensing and GIS, and landscape metrics can provide more spatially consistent and detailed information on landscape structure, which will facilitate the identification of the social and biophysical processes that drive these changes (Herold et al., 2005; Kamusoko and Aniya, 2006).

Subtropical thicket vegetation is found within the Eastern and Western Cape Provinces of South Africa. It is dominated by succulent thicket species such as Portulcaria afra, Sideroxylon inerme and Plumbago auriculata, characterised by a dense spiny evergreen shrubland to low forest. Spekboom (Portulacria afra) in particular, can store carbon in excess of 200 tons per hectare (Mills et al., 2005). It is the source of most of above ground carbon stocks to the ecosystem (Mils and Cowling, 2006; Lechemere et al., 2008; Powell, 2009). Lechemere et al.(2005) and Mils et al. (2007) highlighted the importance of subtropical thicket for carbon sequestration, forage for livestock, wildlife and biodiversity. Despite this, scholars have reported extreme levels of $t$ degradation of the subtropical thicket biome over the recent past (Palmer et al., 2004; Sigwela, 2006, 2009; Kerlet et al., 2006; Luijk et al.,2014; Rutherford et al., 2012).

According to Lechemere et al.(2005), spekboom thicket is susceptible to devastating damage by browsing animals; heavy browsing can transform dense closed thicket into open clumps consisting of scattered and degraded thicket clusters and isolated trees. Studies have revealed that once degraded, spekboom has very limited chances of regeneration (Lechemere et al., 2005a). It has also been noted that thicket degradation leads to structural simplification of vegetation, losses in biomass, carbon stock losses and land degradation (Rutherford et al., 
2012). Therefore subtropical thicket degradation has been regarded as a major concern by many researchers in the recent times (Mills et al., 2007, 2010; Powell, 2009; Cowling and Mills, 2011; Rutherford, 2012; Luijik et al., 2013).

While a lot has been reported on subtropical thicket degradation, little work has been done to understand the temporal trends in subtropical thicket cover change. An analysis of the rate of thicket degradation and fragmentation over a certain period is vital, as it aligns with the objectives of the Mega conservancy Network, which include the protection of important and sensitive natural areas (Knight and Cowling 2003).

Spatial and temporal analyses of land cover change are vital for integrated management of natural resources and the implementation of subtropical thicket restoration programmes. Such information is valuable for refining land management activities, as a baseline for restoration of degraded landscapes and policy formulation. A study by Schoeman et al. (2013) noted that land cover change serves as the baseline for land analysis and management. Fragmentation is the primary threat to terrestrial biodiversity (Armsworth et al., 2014). Hence, analysing land cover change and fragmentation would enable land managers and researchers to answer questions on the drivers of vegetation change and degradation hotspots.

In the present study, land cover changes and fragmentation dynamics within the subtropical thicket are analysed in the GFRGR and its environs from 1972 to 2010 . Temporal change detection was accomplished using the object-oriented post-classification comparison technique. Insights into landscape fragmentation dynamics within the subtropical thicket biome were gained by computing and analysing landscape metrics.

\section{Material and methods}

The study area is located between longitudes $26^{0} \quad 32^{\prime} 25.6914$ "; $27^{0} 4^{\prime} 50.5374$ " E and latitudes $-32^{0} 55^{\prime} 58.2204$ "; $-33^{0} \quad 20^{\prime} 50.8734$ " S (Figure 1). It consists of the Andries Vosloo Kudu Reserve, the Double Drift and the Sam Knott Nature Reserves. The surrounding environments include private commercial farms and the immediate highly populated communal villages of Glenmore, Tyefu, KwaNdlambe, Chisira and Ncabasa, (Figure 1). 
Land management strategies vary between commercial farms and communal villages. Whereas most commercial farmers maintain low stocking rates, rotational grazing and controlled-burning farming strategies, communal farms are overstocked and overgrazed. Subsistence dryland farming is practised in most communal villages; irrigation farming is practiced as well in parts of Tyefu village (Birch et al 2000; Mafengu, 2007).

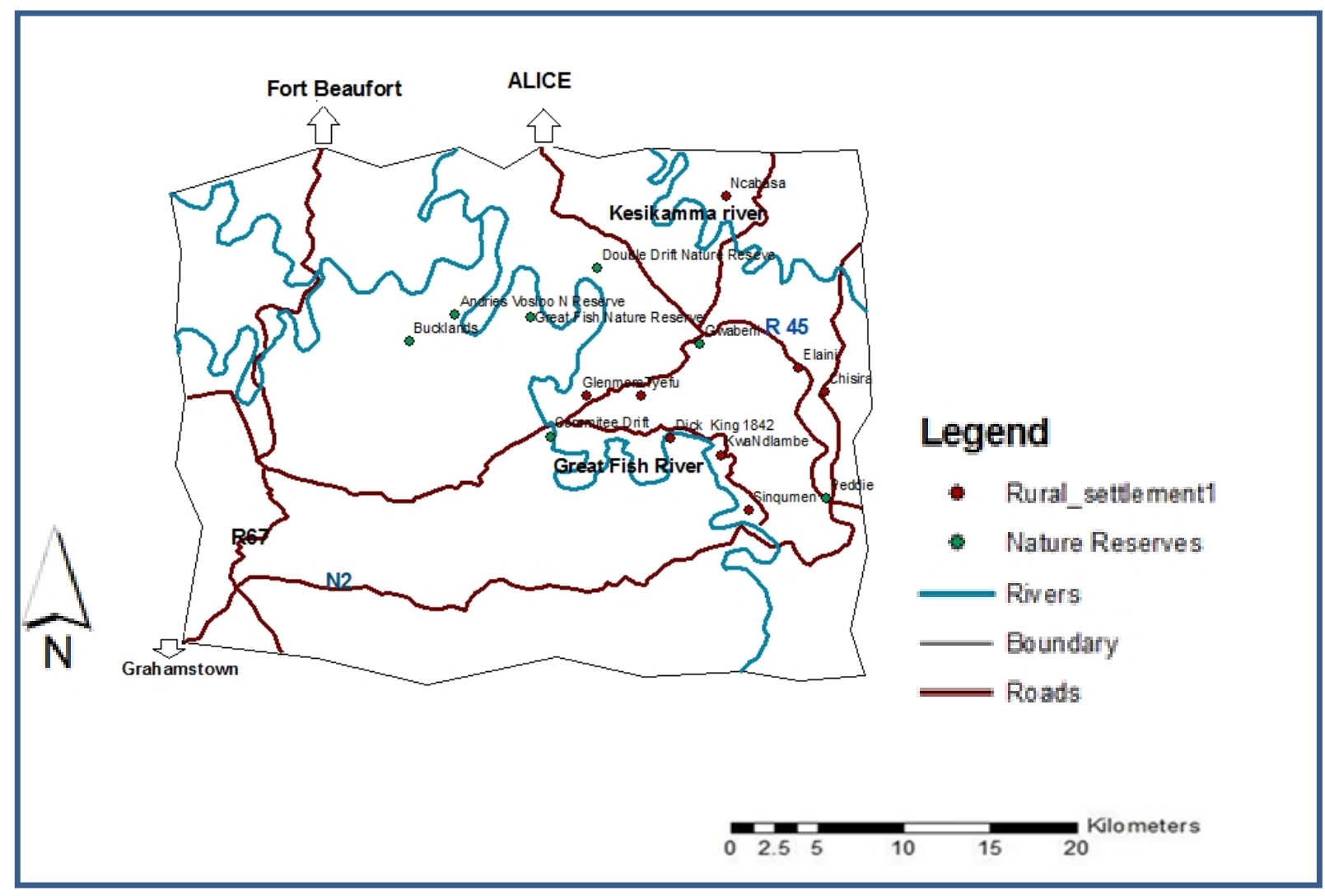

Figure 1: Study area.

\section{Data sources}

Datasets comprising LandSAT MSS, LandSAT4TM, LandSAT 7ETM and SPOT 5, a 20m DEM and 1:50 000 topographic maps were used in the study. LandSat satellite imagery was chosen because of its huge data archive, which dates back to 1972 (Chander et al ., 2004, 2007). The higher resolution SPOT HRG was identified as appropriate for benchmarking the present land cover/ vegetation conditions (Brown et al., 2005; Brown and Pearson, 2005; Pearson et al., 2005b). The satellite images acquired were captured on 20 November 1972, 20 December 1982, 15 December 1992 and 1 December 2002, and 25 December 2010 for 
LandSAT MSS, LandSAT4TM, LandSAT 7ETM and SPOT 5 HRG respectively. All imagery sets acquired were captured on cloudless days in the summer season to ensure clearly distinguishable spectral reflectance patterns of the different vegetation surfaces. Other datasets such as aerial photographs, topographic maps and SPOT 5 at $10 \mathrm{~m}$ resolution were also acquired for accuracy assessment.

\section{Image Processing}

A subset image covering the study area was extracted from the respective images. Geometric and radiometric correction is required for reliable change detection using satellite imagery. Orthorectification was used to correct different angles, which are typical of multi-temporal datasets and to ensure that the images overlay perfectly with other GIS datasets. Temporal image datasets (LandSAT MSS, LandSAT4TM, LandSAT 7ETM and SPOT HRG) were georeferenced to a $5 \mathrm{~m}$ SPOT mosaic and projected to the Universal Transverse Mercator (UTM) system using the World Geodetic System, zone 11, 1984 datum. A 20m DEM was used to correct relief displacement caused by local topography (Campbell et al., 2002; Canty et al., 2004).

\section{Classification method}

Image classification was carried out using the Standard Nearest Neighbour Classification algorithm, as a component of the object-oriented classification approach. A supervised classification technique uses selected image objects as training data. The LandSAT MSS, LandSAT4TM and LandSAT 7ETM and SPOT 5 HRG were segmented into objects by a multi-resolution image segmentation algorithm. The algorithm integrates both spectra and spatial information in the image phases, resulting in meaningful image objects, which carry typical characteristics of land cover compared to pixels. The homogeneity criterion of the multi-resolution segmentation algorithm measures how homogenous or heterogeneous an image object is within itself ( Buyantutev and $\mathrm{Wu}, 2007$ ). The images were independently classified and the post-classification comparison technique was then performed. This was done to overcome uncertainty caused by using multi-temporal images of different spatial resolution (Shao and Wu 2008; Mhangara 2011 and Zhou et al ., 2009). 
Five land cover classes were designated based on Anderson et al. (1976) and the authors' knowledge of the study area. Table 1 below describes the land cover classes used in the present study.

Table 1. Definition of land cover classes

\begin{tabular}{|c|c|}
\hline Land cover & Description \\
\hline Intact thicket & $\begin{array}{l}\text { Dense crystalline thicket which varies from an impenetrable tangle of shrubs to short } \\
\text { trees. } \\
\text { Usually interwoven with woody climbers and often many succulents, especially aloes } \\
\text { and spekboom (Portulacaria afra). }\end{array}$ \\
\hline $\begin{array}{l}\text { Transformed } \\
\text { thicket }\end{array}$ & $\begin{array}{l}\text { Areas with extensive replacement of dense closed-canopy thicket such as savannah of } \\
\text { remnant trees with an ephemeral field layer. } \\
\text { - It has less stable thicket due to a significant loss of plant diversity, high adult } \\
\text { mortality and little successful recruitment. }\end{array}$ \\
\hline $\begin{array}{l}\text { Degraded } \\
\text { Thicket }\end{array}$ & $\begin{array}{l}\text { Sparsely vegetation thicket type. } \\
\text { - It contains sparse vegetation with very low plant cover value as a result of } \\
\text { overgrazing, woodcutting, etc. }\end{array}$ \\
\hline Grasslands & $\begin{array}{l}\text { Biome dominated by grass as the major plant family (Gramineae) and as the } \\
\text { dominant taxa of the predominant plant growth. Growth dominant taxa of the } \\
\text { predominant plant growth. }\end{array}$ \\
\hline Bare surface & Land areas of exposed soil surface as a result of human impacts. \\
\hline
\end{tabular}

\section{Land cover change detection analysis}

Cross-classification was used to analyse the spatial and temporal distribution of the respective land cover classes for 1972-1982, 1982-1992, 1992-2002 and 2002-2010 intervals. The cross-tab function algorithm in IDRISI Kilimanjaro remote sensing software was used to perform the cross-classification process. The land use cover categories of the images in the sets 1972-1982, 1982-1992, 1992-2002 and 2002 -2010 were compared (see Coppen et al., 2004; Narumalani et al., 2004; Kamusoko and Aniya, 2006 and Mhangara, 2011). The 
resultant land cover maps for 1972, 1982, 1992, 2002 and 2010 were then exported to FRAGSTATS 3.3® for landscape metric fragmentation analysis, described below.

\section{Landscape Fragmentation}

The Landscape class level metric function algorithm in FRAGSTATS 3.3® was used to compute landscape fragmentation for the resultant classified images for 1972, 1982, 1992, 2002 and 2010 (Pan et al., 2005). Two landscape metrics, the Number of Patches (NP) and Largest Patch Index (LPI), were used in this study to interpret the dynamics of land cover. The NP represents the numbers of patches within each classes (McGarigal et al., 2002) while LPI refers to the largest patch in each land cover class in a given area. A decrease in LPI signifies an increase in fragmentation and hence an increase in degradation. Classified images were exported to ArcGIS 10 and converted into polygons. A patch analyst extension in ArcGIS 10 with FraGSTATS 3.3 interface was then used to compute the NP and LPI statistics for each cover class. The analysis procedure used was adapted from McGarigal et al., 2002, Nagendra et al., 2004 and Kamusoko\& Aniya 2006.

\section{Validation datasets}

The validation of 1972, 1982, 1992 and 2002 classes was done by identifying features on the satellite images that could be still identified in the field. Features such as dams, settlement centroids, plantations and clumps of subtropical thicket vegetation were used as reference points. A centimetre level precision Ashtech ${ }^{\circledR P r o M a r k 2}{ }^{\mathrm{TM}}$ Global Positioning System (GPS) receiver was used to validate reference points in the field. At least 90 ground reference points were collected per class, hence a total selection of 450 reference points for all the classes. The class size determined the number of reference points to be collected. The points were converted into shape files and exported to the object-oriented GIS software, where they were overlaid on the segmented satellite image to extract pixels for training tests. 


\section{Results}

\section{Temporal changesinland cover}

Land cover classification maps for 1972-2010 are presented in Figure 2. Validation of the classification results proved that the object-oriented classification produced reliable land cover maps. All the overall accuracies were higher than 0.80 and the Kappa Index of Agreement (KIA) was above 0.82 (Table 2).

Table 2: Classification accuracy assessment summary

\begin{tabular}{|c|c|c|}
\hline Year & Overall Accuracy Assessment & Kappa Index of Agreement (KIA) \\
\hline 1972 & 84 & 0.91 \\
\hline 1982 & 90 & 0.92 \\
\hline 1992 & 91 & 0.88 \\
\hline 2002 & 84 & 0.91 \\
\hline 2010 & 94 & 0.86 \\
\hline
\end{tabular}

Figure 2 and Table 3 below illustrate the decadal land cover changes for the 1972-2010 period.

Table 3 Land cover changes from 1972 - 2010

\begin{tabular}{|l|l|l|l|l|l|}
\hline Class & $\begin{array}{l}\mathbf{1 9 7 2} \\
\mathbf{\%}\end{array}$ & $\begin{array}{l}\mathbf{1 9 8 2} \\
\mathbf{\%}\end{array}$ & $\begin{array}{l}\mathbf{1 9 9 2} \\
\mathbf{\%}\end{array}$ & $\begin{array}{l}\mathbf{2 0 0 2} \\
\mathbf{\%}\end{array}$ & $\begin{array}{l}\mathbf{2 0 1 0} \\
\mathbf{\%}\end{array}$ \\
\hline Intact thicket & 50 & 40 & 25 & 16 & 10 \\
\hline $\begin{array}{l}\text { Transformed } \\
\text { thicket }\end{array}$ & 35 & 30 & 25 & 15 & 14 \\
\hline Degraded thicket & 10 & 20 & 35 & 40 & 44 \\
\hline Grassland & 03 & 0.4 & 06 & 13 & 14 \\
\hline Bare surfaces & 02 & 0.6 & 09 & 16 & 18 \\
\hline
\end{tabular}

As illustrated in Table 3, there is a general decrease in intact and transformed thicket, while degraded thicket, grassland and bare surface classes increased. 
1972

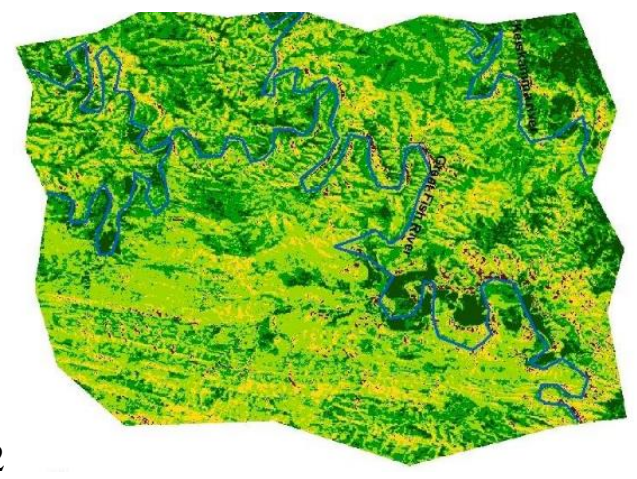

1992

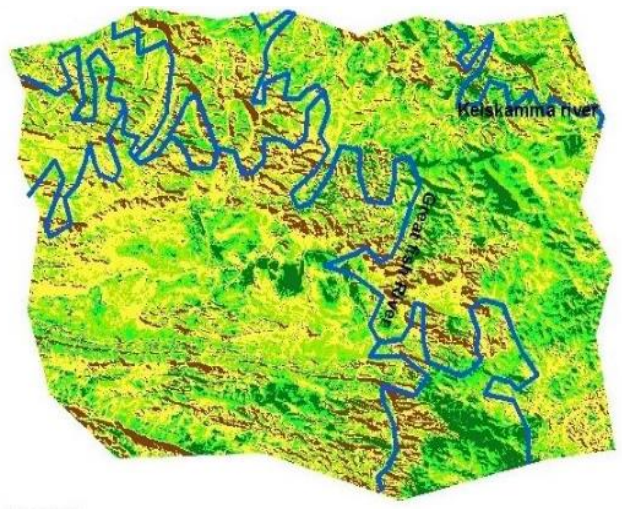

2010

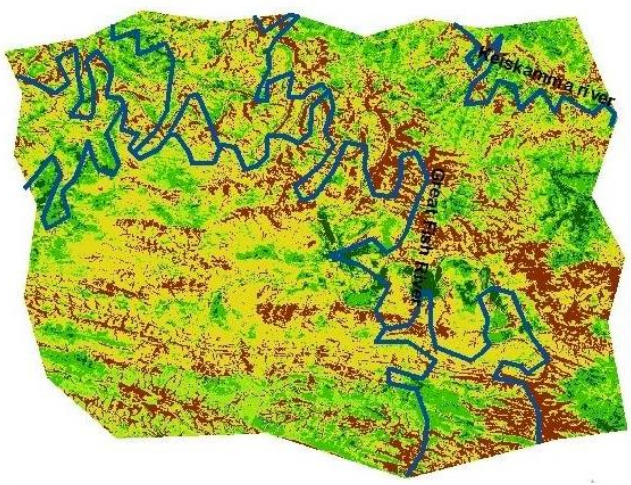

1982

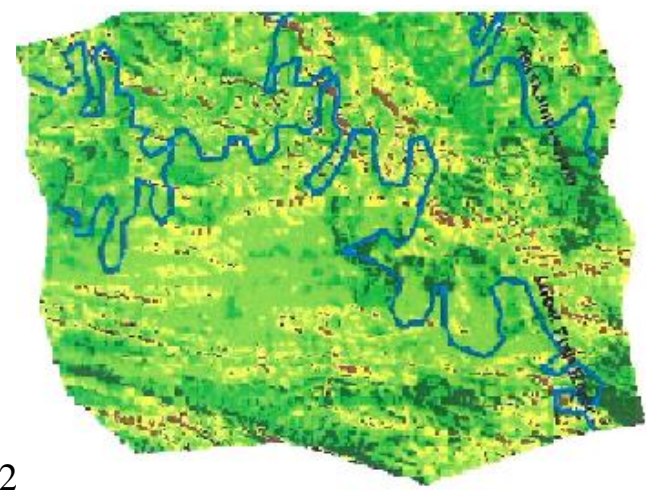

2002
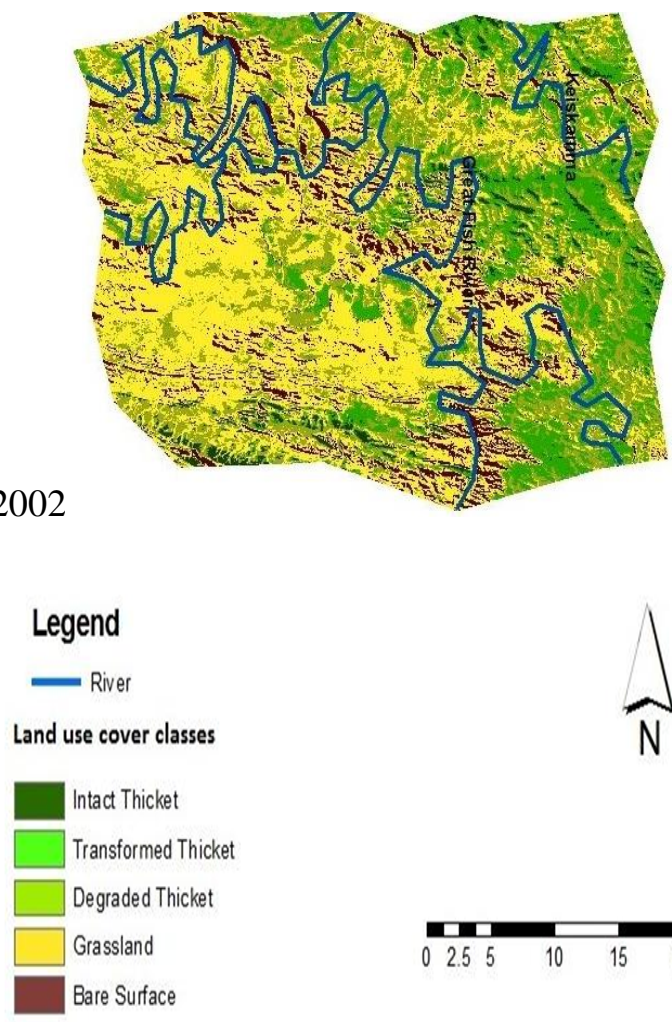

\begin{tabular}{llllll}
\hline & 25 & & & & \\
0 & 2.5 & 10 & 15 & 20
\end{tabular}

Figure 2: 1972 -2010 Land cover maps.

\section{Land cover fragmentation trends}

As illustrated in Figure 3, there was an increase in the NP of intact and transformed thicket, and a corresponding decrease in degraded thicket, grassland and bare-surface classes respectively. This denotes a fragmentation of intact and transformed thicket classes and an expansion of the degraded thicket, grassland and bare surface classes. As can be noted from Figure 4, there was a general decrease in the LPI of the intact and transformed thicket classes, 
which denotes thicket degradation in these classes over time. A gradual increase of the LPI for degraded, grasslands and bare-surface for the same period denotes an expansion of these cover classes.

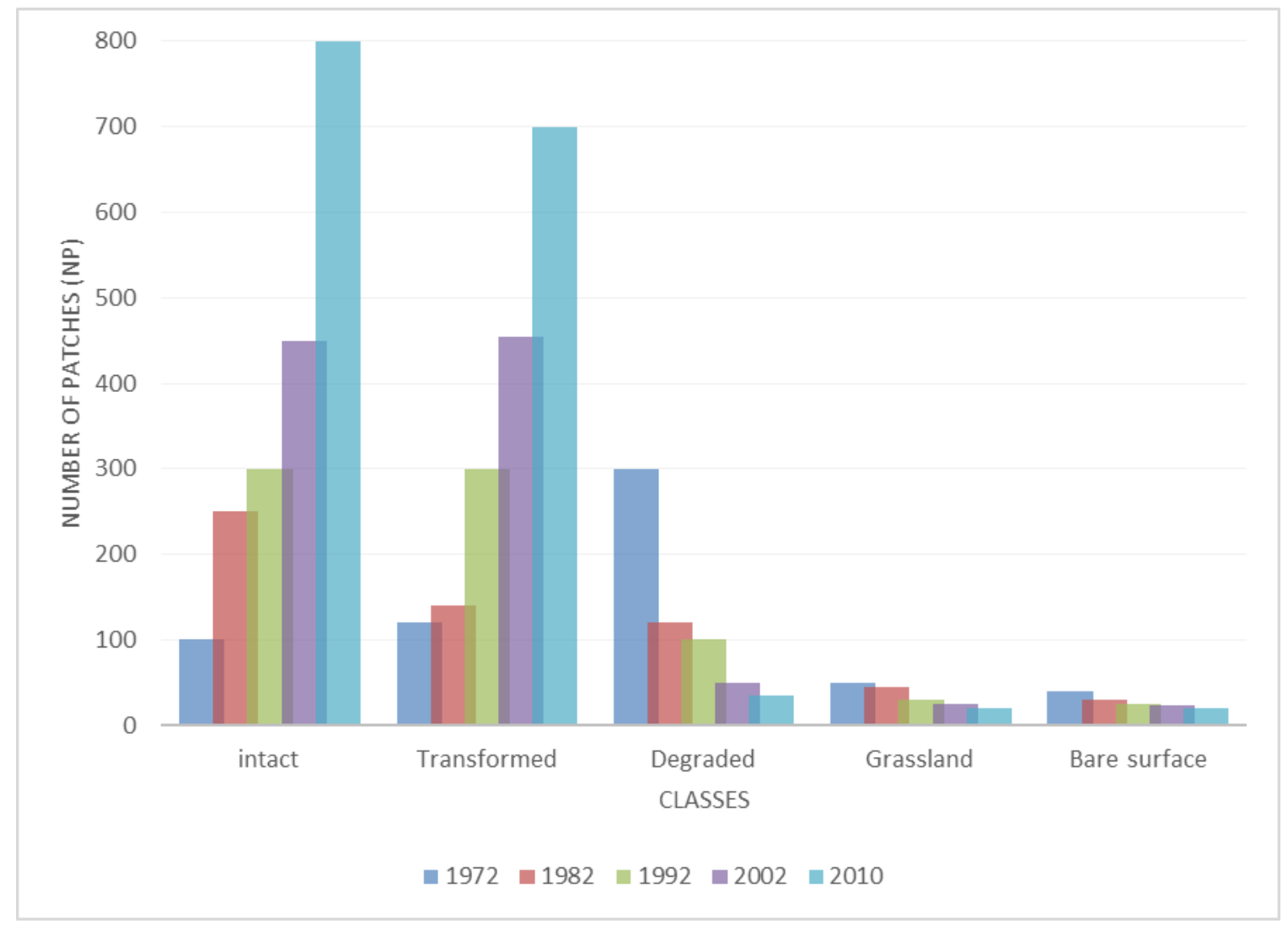

Figure 3 Changes in Number of Patches (NP) from 1972 to 2010 


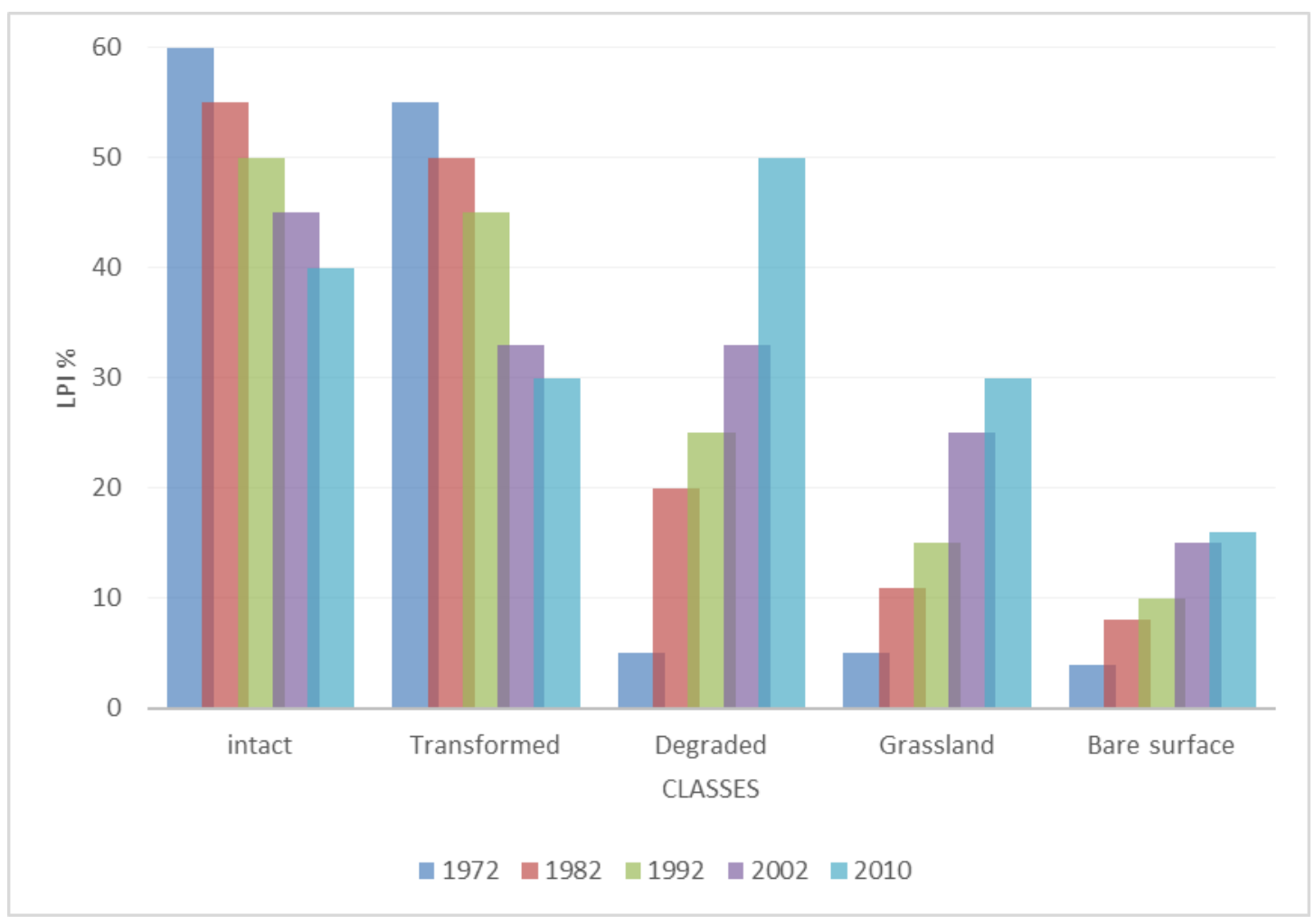

Figure 4: Changes in the Largest Patch Index (LPI) from 1972 to 2010.

\section{Discussion}

The use of object-oriented classification has produced high classification accuracy of the land use/cover classes, which are relatively free of the mixed-pixel effect. The creation of image objects as classes has facilitated the processes of analysing fragmentation and change detection dynamics within land cover classes. The pattern and structure of the objects were distinguishable through time. A decrease in intact and transformed thicket classes, as well as an increase in degraded thicket, grasslands and bare surface are the most significant cover change patterns identified in the GFRGR and its environs. Kakembo and Rowntree (2003), and Sigwela et al (2009) also noted thicket transformation and degradation in the area. They attributed the trends and patterns to differences in land tenure systems. Commercial farms and protected areas (game reserves) had limited vegetation degradation, as opposed to the communally owned lands, which were characterised by overgrazing and severe soil erosion forms related to land abandonment (Kakembo and Rowntree, 2003). During field observations, high thicket degradation and transformation, bare surface and severe gully erosion were observed in the communal grazing lands and highly populated settlements surrounding the GFRNR. The collection of wood for fuel has decimated thicket cover near 
these villages, such that a distinct vegetation gradient is discernible with a distance away from communal village.

The landscape metric analysis clearly illustrates an increase in vegetation fragmentation over the 38-year period, as demonstrated by an increase in the NP and decrease of the LPI for intact and transformed thicket. Kerley and Landman (2006) revealed similar trends in their study on patterns and implications of transformation in subtropical thicket of the Eastern Cape Province of South Africa. They observed that browsing goats result in the extensive replacement of the closed canopy by pseudo savannah in remnant trees. Sigwela et al. (2006) also observed that elephants have a negative impact on thicket that can result in the extinction of some thicket species. The increasing thicket degradation trend is further corroborated by the findings of Volkand Euston (2002). In their estimation of vegetation degradation using remote sensing within the Subtropical Thicket Ecosystem Planning (STEP) project, approximately $60 \%$ of the original surface area of the inland semi-arid thicket vegetation has been severely degraded.

\section{Conclusions}

Based on the land cover analysis of Landsat MSS, TM, ETM and 2010 SPOT 5 HRG data between 1972 and 2010, it has been identified that the decimation of intact thicket is the major vegetation change trend, at the expense of which degraded thicket, bare areas and grassland cover classes have increased. The conversion of transformed thicket to grasslands, degraded thicket to grassland and bare surfaces, are other significant land cover changes. Landscape metric analyses revealed that thicket vegetation has become more fragmented, characterized by smaller, less linked patches of the intact thicket. The landscape metrics for the intact and transformed thicket classes reflect an increase in the NP and a decrease in the LPI. Vegetation fragmentation is mainly a product of anthropogenic activities, such as overgrazing, indiscriminate wood collection for fuel and other injudicious land use practices. The findings of the present study enhance our understanding of the dynamic nature of land use/cover changes from 1972 to 2010 due to the human impact on the subtropical thicket. 
South African Journal of Geomatics, Vol. 4, No. 4, November 2015

\section{Acknowledgements}

The authors wish to thank the National Research Foundation of South Africa (NRF) for funding this project and the South African National Space Agency for providing satellite imagery. We are greatly thankful to N. Ndou, B. Mazeka .and J. Smith for their assistance during fieldwork. 


\section{References}

Amissah - Arthur, A., Miller R. B. (2002). Remote sensing applications in African agriculture and natural resources: Highlighting and managing the stress of increasing population pressure. Advances in Space Research, (30), 2411 - 2421.

Armsworth, P.R.; Kendall, B.E.; Davis, F.W. 2004. An introduction to biodiversity concepts for environmental economists. Resource and Energy Economics, 26, 115-136.

Buyantuyev, A., Wu, J. (2007). Effects of thematic resolution on landscape pattern analysis. Landscape Ecology. (22), 7 - 13.

Canty, M. J., Nielsen, A. A., \& Schmidt, M. (2004). Automatic radiometric normalization of multitemporal satellite imagery. Remote Sensing of Environment 91(3-4), 441-451

Coppen, P., Jonckheere, I., Nackaerts, K., Muys, B., (2004). Digital change detection methods in ecosystem assessing: A review. International Journal of Remote Sensing, (25), 9, 1596-1600.

Cowling, R.M., Mills, A.J., 2011. A preliminary assessment of rain through fall beneath Portulacaria afra canopy in subtropical thicket and its implications for soil carbon stocks. South African Journal of Botany, 77, 236-240.

Campbell, J. B. (2002) Introduction to Remote Sensing. Guilford Press, New York, 3, 25-40.

De Mûelenaere, S., Frankl, A., Mitiku Haile, Poesen, J., Deckers, J., Munro, R.N., Veraverbeke, S., Nyssen, J., 2013. Historical landscape photographs for calibration of Landsat land use/cover in the northern Ethiopian highlands. Land Degradation \& Development

Houghton RA. (1994). The worldwide extent of land-use change. Bioscience 44 (5): 305-313.

Herold, M., Couclelis, H., Clarke, C. (2005). The role of spatial metrics in the analysis of urban land use change. Computers, Environment and urban Systems, 29: 369-399.

Green K, Kempka D, Lackey L. (1994). Using remote sensing to detect and monitor landcover and land-use change. Photogrammetric Engineering and Remote Sensing, 60 (3): $331-337$.

Lal, R. (2007). Soil science and the carbon civilization. Soil Science Society of American Journal, (71), 4, 1425-1437. 
Lechmere-Oertel, R.G., Kerley, G.I.H., Cowling, R.M., 2005a. Patterns and implications of transformation in semi-arid succulent thicket, South Africa. Journal of Arid Environments, 62, 459-474.

Lechmere-Oertel, R.G., Kerley, G.I.H., Cowling, R.M., 2005b. Landscape dysfunction and reduced spatial heterogeneity in soil resources and fertility in semi-arid succulent thicket, South Africa. Australian Ecology, 30, 615-624.

Lechmere-Oertel, R.G., Kerley, G.I.H., Mills, A.J., Cowling, R.M., 2008. Litter dynamics across browsing-induced fenceline contrasts in succulent thicket, South Africa, South African Journal of Botany, 74, 651-659.

Lloyd J.W., van den Berg E., van Wyk E., Palmer A.R., 2002. Patterns of Degradation and Transformation in the Thicket Biome. Unpublished Report, Terrestrial Ecology Research Unit, Dept of Zoology, University of Port Elizabeth, South Africa. www.zoo.upe.ac.za/step.

Luijik Van .G Cowling R.M, Risken M.J.P, Glenday J (2013) Hydrological implication of desertification: Degradation of South African semiarid subtropical thicket, Journal of Arid Environments, 91, 14-21.

Kamusoko, C and Aniya, M. (2006). Land use/cover change and landscape fragmentation analysis in the Bindura district, Zimbabwe. Land Degradation and Development, (18), 2, 221-233.

Kakembo, V. and Rowntree, K. M., (2003). The relationship between land use and soil erosion in the communal lands near Peddie town, Eastern Cape South Africa. Land Degradation \& Development, 14: 39-49.

Kerley, G, H, I and Landman, M. (2006). The impacts of elephants on biodiversity in the Eastern Cape Subtropical thickets. African Journal of Science (93), 231-236.

McGarigal, K., Cushman, S. A., Neel, M. C. (2002). FRAGSTATS Spatial pattern analysis program for categorical maps. Computer software program. University of Massachusetts, Amherst, (2), 3 - 66.

Mhangara, P. (2011). Land use/cover change modelling and Land degradation assessment in the Keiskamma catchment using remote sensing and GIS. PhD thesis Nelson Mandela Metropolitan University.

Mills, A.J., Cowling, R.M., 2010. Below-ground carbon stocks in intact and transformed subtropical thicket landscapes in semi-arid, South Africa. Journal of Arid Environments, 74, 93-100. 
Mills, A.J., Fey, M.V., 2004. Transformation of thicket to savannah reduces soil quality in the Eastern Cape, South Africa. Plant and Soil 265, 153-163.

Mills, A.J., Cowling, R.M., Fey, M.V., Kerley, G.I.H., Donaldson, J.S., Lechmere-Oertel, R.G., Sigwela, A.M., Skowno, A.L., Rundel, P.W., 2005. Effects of goat pastoralism on ecosystem carbon storage in semi-arid thicket, Eastern Cape, South Africa. Austral Ecology 30, 797-804.

Mills, A.J., Cowling, R.M., Fey, M.V., Kerley, G.I.H., Donaldson, J.S., Lechmere-Oertel, R.G., Sigwela, A.M., Skowno, A.L., Rundel, P.W., 2005. Effects of goat pastoralism on ecosystem carbon storage in semi-arid thicket, Eastern Cape, South Africa. Austral Ecology 30, 797-804.

Mills, A.J., Turpie, J., Cowling, R.M., Marais, C., Kerley, G.I.H., Lechmere-Oertel, R.G., Sigwela, A.M., Powell, M., 2007. Assessing costs, benefits and feasibility of subtropical thicket restoration in the Eastern Cape, South Africa. In: Aronson, J., Milton, S.J., Blignaut, J. (Eds.), Restoring Natural Capital. Science, Business and Practice. Island Press, Washington DC, pp. 179-187.

Nagendra, H., Munroe, D. K, Southworth, J. (2004). From pattern to process: Landscape fragmentation and analysis of land use/ cover change. Agriculture, Ecosystems and Environment, (91), 478-489.

Narumalani, S., Mishra, D. R. M., Southworth, J. (2004). Change detection and landscape metrics for inferring anthropogenic processes in greater EFMO area. Remote Sensing of the Environment, (23), 101-115.

Ojima DS, Galvin KA, Turner BL. (1994). The global impact of land-use change, Bioscience 44 (5): 300-304.

Parker J.A Robert V, Troxel D.E (1983). Comparison of interpolating methods for image resampling. IEEE Transtions on medical imaging,Vol. MI-2 NO 1,31-39

Petit C, Scudder T, Lambin E. (2002). Quantifying processes of land-cover change by remote sensing: resettlement and rapid land-cover changes in south-eastern Zambia. International Journal of Remote Sensing, 22 (17): 3435-3456.

Prentice. (2007). Dynamic global vegetation modelling quantifies terrestrial ecosystem response to large-scale environment change. Terrestrial Ecosystems in a Changing World Global Change - the IGBP Series, (50), 175-192.

Powell, M., 2009. Restoration of Degraded Subtropical Thickets in the Baviaanskloof Megareserve, South Africa. MSc thesis, Department of Environmental Sciences, Rhodes University, South Africa. 
Rutherford M.C, Powrie L.W, Husted L.B (2012). Herbivore-driven land degradation: Consequences for plant diversity and soil in arid subtropical thicket in South Eastern Africa. Land Degradation \& Development.

Rutherford, M.C, Pourie, L.W (2010). Severely degraded rangeland: Implications for plant diversity from case study in succulent Karoo, South Africa. Journal of Arid Environment. 74, 692-701.

Sanchez-Azofeifa, G. A., K. L., Castro-Esau, W. A., Kurz and A. Joyce. (2009). Monitoring carbon stocks in the tropics and the remote sensing operational limitations: from local to regional projects. Ecological Applications, (19), 480 494.

Southworth, J., Nagendra, H., Carlson, L. A., Tucker, C., M. (2004). Assessing the impact of Celaque National Park on forest fragmentation in Western Honduras. Journal of Applied Geography, (24). 303 - 322.

Shao G, Wu J. (2008). On the accuracy of Landscape pattern analysis using remote sensing data. Landscape Ecology, (23), 505-511.

Sigwela, A. M., Lechemere-Oertel, R. G, Kerley, G .I. H., \& Cowling, R. M. (2006). Effects of transformation on wood Plant Dynamics in the succulent thicket of the. Proceedings of the Subtropical Thicket Ecosystem Planning Project (STEP). Centre for African Conservation Ecology Thicket forum Report. Nelson Mandela Metropolitan University, South Africa, (4), 43-45.

Sigwela, A. M., Kerley, G. I. H., Mills, A.J., Cowling, R. M. (2009). The impacts of browsing-induced degradation on the reproduction of subtropical thicket canopy shrubs and trees. South Africa Journal of Botany, (75), 262-267.

Zhou, W., Huang, G., Troy, A., Cadenarzo. L. (2009). Object-based land cover classification of shaded areas in high spatial resolution imagery of urban areas, a comparison study. Remote Sensing of the Environment, (113), 8, 1769-1777. 